\title{
Facile fabrication of composition-tunable Fe/Mg bimetal- organic frameworks for exceptional arsenate removal
}

Yue Gu, ${ }^{\mathrm{a}, \mathrm{b}}$ Donghua Xie, ${ }^{\mathrm{a}, \mathrm{b}}$ Yongchuang Wang, ${ }^{\mathrm{a}, \mathrm{b}}$ Wenxiu Qin, ${ }^{\mathrm{a}, \mathrm{b}}$ Haimin Zhang, ${ }^{\mathrm{a}}$ Guozhong Wang, ${ }^{a}$ Yunxia Zhang, ,a Huijun Zhao a,c

${ }^{a}$ Key Laboratory of Materials Physics, Centre for Environmental and Energy

Nanomaterials, Anhui Key Laboratory of Nanomaterials and Nanotechnology, CAS Centre for Excellence in Nanoscience, Institute of Solid State Physics, Chinese Academy of Sciences, Hefei 230031, China.

${ }^{b}$ University of Science and Technology of China, Hefei 230026, P. R. China

${ }^{c}$ Centre for Clean Environment and Energy, Griffith University, Gold Coast Campus, Queensland 4222, Australia.

\begin{abstract}
The rational design of metal-organic frameworks with tailored components and structural features is crucial for achieving the desired functions and expanding the emerging applications. Herein, water-stable bimetallic $\mathrm{Fe} / \mathrm{Mg}$ metal-organic frameworks (Fe/Mg-MIL-88B) have been successfully fabricated through a facile and effective one-step strategy to access the exceptional arsenic decontamination. Notably, the obtained bimetallic Fe/Mg-MIL-88B architectures are demonstrated to possess a well-defined spindle-like morphology. Interestingly, the Fe/Mg molar ratios within the resultant Fe/Mg-MIL-88B frameworks can be flexibly modulated on demand, leading to the variation of the structural features associated with length/diameter ratio and unit cell parameters along with surface areas. Thanks to the unique structural and compositional merits as well as the synergetic contribution from two active metal centres, the fabricated Fe/Mg-MIL-88B nanospindles exhibit enhanced decontaminant performance toward arsenate in terms of ultrafast sorption kinetics and high sorption capacities, compared to the monometallic Fe-MIL-88B.

${ }^{*}$ Correspondence Author. Email: yxzhang@issp.ac.cn Fax: +86-551-65591434; Tel: +86-551-65592145
\end{abstract}


Impressively, an extraordinary arsenate uptake capacity up to $303.6 \mathrm{mg} / \mathrm{g}$ is achieved in the optimized $\mathrm{Fe} / \mathrm{Mg}-\mathrm{MIL}-88 \mathrm{~B}$ with $\mathrm{Fe} / \mathrm{Mg}$ feeding ratio of 0.5 , which is substantially superior to most of the reported arsenic absorbents. More significantly, these $\mathrm{Fe} / \mathrm{Mg}-\mathrm{MIL}-88 \mathrm{~B}$ absorbents possess exceptional regenerative ability and stability during multiple sorption/desorption cycles, as reflected by the negligible drop in arsenic removal efficiency and excellent maintenance of the crystalline structure and morphology integrity. All these satisfactory results prefigure that the designed bimetallic Fe/Mg-MIL-88B absorbents hold a great promise for the in-depth purification of arsenic-contaminated water.

Keywords: bimetallic; composition-tunable; Fe/Mg-MIL-88B; arsenate; adsorption

\section{Introduction}

Arsenic (As) is regarded as one of notorious substances among the widespread contaminants existing in the aquatic environment. As previously reported, long-term exposure to arsenic-contaminated water may result in severely chronic and acute toxicity, various types of cancer, and even death [1]. It is more terrible that arsenic species possess high mobility and may easily be accumulated in human body via the food chain [2]. In addition to natural geochemical processes, anthropogenic activities are worsening the situation associated with arsenic pollution. Specifically, typical arsenic concentration in contaminated groundwater and industrial wastewater is far beyond the maximum contaminant level of arsenic in drinking water of $10 \mathrm{ppb}$ set by the World Health Organization (WHO) [3]. Faced with huge toxicity and carcinogenic effect as well as continuously soaring levels from arsenic species, there is an urgent demand to explore practical and effective technologies to eliminate arsenic contaminant from aquatic environments.

Among most common arsenic treatment techniques based on flocculation, adsorption, ion exchange, membrane separation and chemical precipitation, adsorption is recognized as one of the most promising and popular ways to remove arsenic contaminants because of its high efficiency, low cost, ease in operation and 
high specificity [4-6]. To the best of our knowledge, the uptake efficiency is closely associated with the surface-to-volume ratio of the adsorbents. In this sense, porous MOFs are supposed to be promising arsenic decontaminant candidates due to their unique structural and physicochemical features, such as versatile architectures, excellent chemical/thermal stability, tunable pore size, large surface area, high accessible active sites, and customizable functionality [7]. As an outstanding representative of water stable MOFs, iron-containing MOFs (e.g., Fe-BTC, MIL-101, MIL-53 and MIL-88B) are deduced to be suitable arsenic scavengers in view of their ready availability, low-cost effectiveness, nontoxic metal source, and strong affinity toward arsenic species [8-11]. Nevertheless, arsenic remediation performance from these monometallic iron-based MOFs is not satisfactory. Hence, arsenate scavengers with enhanced capture performance are still in demand from the viewpoint of both fundamental studies and practical applications.

To date, researchers have continuously focused on engineering MOF materials with the purpose of boosting the resulting performance by incorporating two or more metal ions into a single framework to form homogeneous bimetallic or multimetallic MOFs, which are expected to integrate the merits of different components and may endow them with some additional properties via the coupling effects. For instance, Yang Jiao et al. showed that bimetallic Mg/Ni-MOF-74 or Mg/Co-MOF-74 samples can significantly improve the water stability without strongly impacting $\mathrm{CO}_{2}$ adsorption loadings as compared to their single metal MOF analogues [12]. Meanwhile, the mixture of $\mathrm{Zr}$ with $\mathrm{Ti}$ in UiO-66 can improve its adsorption capacity toward $\mathrm{CO}_{2}$ [13]. Similarly, bimetal CoZn-ZIF-8 demonstrated increased pore volume and BET surface area when compared to monometallic ZIF-8 [14]. Besides, Gia-Thanh Vuong et al. obtained bimetallic $\mathrm{Fe}_{2} \mathrm{Ni}-\mathrm{MIL}-88 \mathrm{~B}$ product which showed a drastic change over the original single metal $\mathrm{Fe}_{3}$-MIL-88B in regard to porosity, and considerably high $\mathrm{N}_{2}$ and $\mathrm{CO}_{2}$ adsorption [15]. Despite great progress achieved so far, the rational fabrication of bimetallic MOFs with controllable composition and tailored performance remains still a great challenge. 
In this work, water stable bimetallic Fe/Mg-MIL-88B with well-controlled spindle morphology has been successfully fabricated via a facile one-step hydrothermal strategy. The morphologies, microstructures and crystalline phase of the resultant bimetallic $\mathrm{Fe} / \mathrm{Mg}-\mathrm{MIL}-88 \mathrm{~B}$ frameworks are systematically studied via various characterization techniques. The molar ratios of $\mathrm{Fe} / \mathrm{Mg}$ are varied in order to understand their effects on the resulting morphology and microstructural features of the final product, which will be conducive to optimize the arsenate uptake performance. The key factors, including sorption kinetics, equilibrium sorption isotherm along with effects of initial $\mathrm{pH}$ and interfering ions, are discussed in detail. The underlying mechanism behind the superior arsenate removal capacity of the bimetallic Fe/Mg-MIL-88B is elucidated by X-ray photoelectron spectroscopy (XPS) and Fourier transform infrared (FT-IR) spectroscopy analyses. Finally, the feasibility of the resulting $\mathrm{Fe} / \mathrm{Mg}-\mathrm{MIL}-88 \mathrm{~B}$ toward arsenate purification is assessed in the realistic complicated environment water sample.

\section{Experimental section}

Bimetallic Fe/Mg-MIL-88B frameworks with various Fe/Mg molar ratios were synthesized following the previous work reported by Gia-Thanh Vuong et al. with a slight modification (Scheme 1) [15]. Briefly, $1 \mathrm{mmol}$ of metal salts with varying the molar ratio of $\mathrm{Fe}^{3+} / \mathrm{Mg}^{2+}(2: 1,1: 1,1: 2)$ combined with $1 \mathrm{mmol}$ of $\mathrm{H}_{2} \mathrm{BDC}$ were dissolved in $10 \mathrm{~mL}$ of DMF under constant stirring to get a homogeneous solution. Subsequently, $2 \mathrm{~mL}$ of $2 \mathrm{M} \mathrm{NaOH}$ solution was rapidly injected to the above mixed solution with continuous stirring for another $15 \mathrm{~min}$. The mixture was then transferred into $25 \mathrm{~mL}$ of Teflon-lined autoclave and heated without agitation in an oven at 100 ${ }^{\circ} \mathrm{C}$ for $15 \mathrm{~h}$. After cooling to room temperature, the resultant suspension was collected by centrifugation and washed several times with DMF and methanol, respectively. Afterwards, the washed sample was dried at $60{ }^{\circ} \mathrm{C}$ for $24 \mathrm{~h}$ in a vacuum for further characterization. As a result, the as-synthesized three products were denoted as Fe/Mg-MIL-88B(n), i.e. Fe/Mg-MIL-88B(2), Fe/Mg-MIL-88B(1), Fe/Mg-MIL- 
$88 \mathrm{~B}(0.5)$, respectively, in which $\mathrm{n}$ represented the feeding ratio of $\mathrm{Fe}^{3+} / \mathrm{Mg}^{2+}$ in the precursors.

In contrast, monometallic Fe-MIL-88B and Mg-MOFs were also synthesized via a similar procedure described above using only $\mathrm{FeCl}_{3} \cdot 6 \mathrm{H}_{2} \mathrm{O}$ or $\mathrm{Mg}\left(\mathrm{NO}_{3}\right)_{2} \cdot 6 \mathrm{H}_{2} \mathrm{O}$ as the metal precursor.
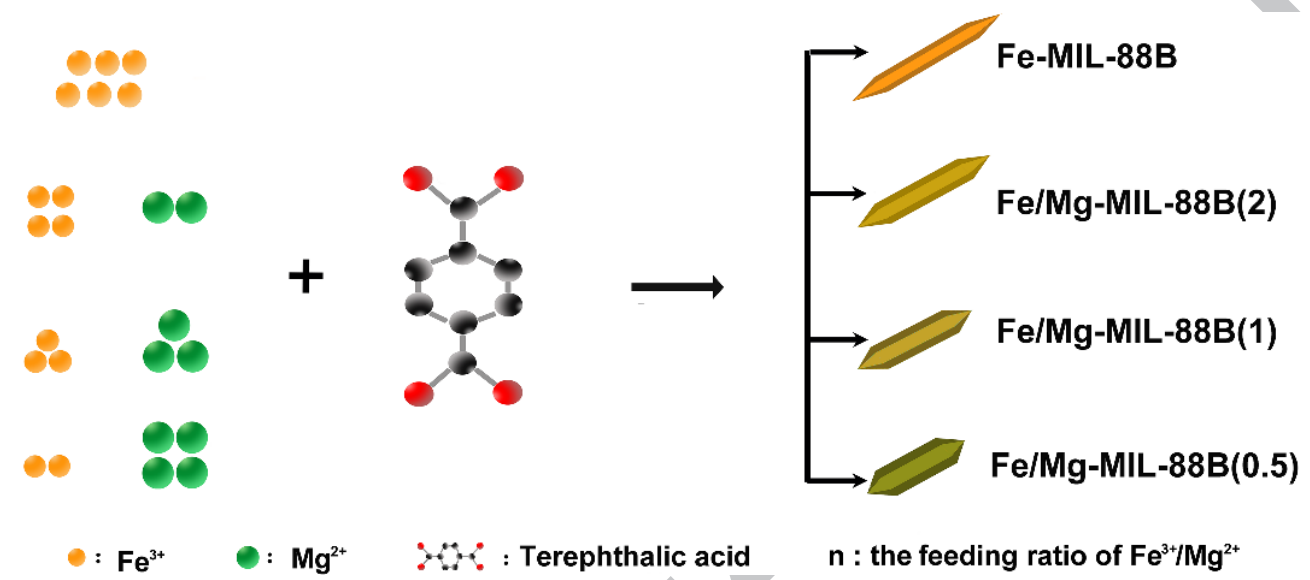

Scheme 1. The schematic of the synthesis process of Fe/Mg-MIL-88B(n). The L/D ratios of Fe/Mg-MIL-88B(n) can be affect by feeding ratio of $\mathrm{Fe}^{3+} / \mathrm{Mg}^{2+}$.

\section{Results and discussion}

\subsection{Morphological and structural characterization}

Single-metallic Fe-MIL-88B are firstly synthesized via a hydrothermal method using $\mathrm{FeCl}_{3} \cdot 6 \mathrm{H}_{2} \mathrm{O}$ and $\mathrm{H}_{2} \mathrm{BDC}$ as precursors. Based on the scanning electron microscope (SEM) observations (Fig. 1a), the pure Fe-MIL-88B exhibits a uniformly hexagonal rod-like morphology with the pointed ends, accompanied by a length of about $600-900 \mathrm{~mm}$ and average diameter of $80 \mathrm{~nm}$. Meanwhile, the average length/diameter (L/D) ratio is approximately 6.56, which is consistent with the previous finding [16]. In addition, the bimetallic $\mathrm{Fe} / \mathrm{Mg}-\mathrm{MIL}-88 \mathrm{~B}(\mathrm{n})$ materials with various feeding ratios of $\mathrm{Fe}$ to $\mathrm{Mg}$ are fabricated via a similar hydrothermal process in the presence of both $\mathrm{FeCl}_{3}$ and $\mathrm{Mg}\left(\mathrm{NO}_{3}\right)_{2}$. SEM images (Fig. 1b-d) show that all of the bimetallic Fe/MgMIL-88B(n) frameworks remain a similar spindle-like morphology, indicative of the coordination flexibility of the bimetallic Fe/Mg-MIL-88B(n) 
architectures. However, the incorporation of $\mathrm{Mg}$ in the framework of Fe-MIL$88 \mathrm{~B}$ results in a slight alteration in their diameter and length. Based on a statistical calculation of more than 50 particles, the distributions of the L/D ratios of the as-prepared bimetallic Fe/Mg-MIL-88B(n) nanospindles with different $\mathrm{Fe} / \mathrm{Mg}$ feeding ratios are given in Fig. S1. Evidently, along with the decrease in $\mathrm{Fe} / \mathrm{Mg}$ molar ratios, the bimetallic Fe/Mg-MLL-88B(n) nanospindles become shorter and broader, accompanied by a smaller L/D ratio. In can be reasonably inferred that the difference in the coordinating reaction of $\mathrm{Fe}^{3+}$ and $\mathrm{Mg}^{2+}$ with $\mathrm{H}_{2} \mathrm{BDC}$ facilitates the subsequent growth of bimetallic Fe/Mg-MIL-88B(n) crystals along a specific lattice plane and limit the growth in other lattice planes, giving rise to the variations of these nanospindles in the ultimate aspect ratios. The phenomenon is in good consistent with the previous reports, in which the incorporation of a second metal element might affect the final morphology of MIL-88B. In a representative work, Shin Ae Park and coworkers revealed that higher incorporation of iron ions into $\left\{\mathrm{Fe}_{\mathrm{x}} \operatorname{In}_{1-\mathrm{x}}\right\}-\mathrm{MIL}-$ 88B tended to produce shorter hybrid $\left\{\mathrm{Fe}_{\mathrm{x}} \operatorname{In}_{1-\mathrm{x}}\right\}-\mathrm{MIL}-88 \mathrm{~B}$ nanobamboos along with lower aspect ratio [17]. In addition, Zhong-Jie Jiang and coworkers found that the coordination difference of each metal ion with ligands might affect the nucleation and growth of $\mathrm{Fe}_{2} \mathrm{M}-\mathrm{MOF}$ crystals, subsequently resulting in the bimetallic MOFs with different diameter and length [18]. Meanwhile, transmission electron microscope (TEM) image (Fig. 1e) further confirms the spindle-like shape of the resulting Fe/Mg-MIL-88B(0.5). The elemental mapping images in Fig. 1f reveals a highly uniform distribution of $\mathrm{Fe}, \mathrm{Mg}, \mathrm{C}$ and $\mathrm{O}$, confirming the coexistence and homogeneous dispersion of both $\mathrm{Fe}$ and $\mathrm{Mg}$ metal centres within the same framework of bimetal Fe/Mg-MIL-88B(0.5) topology. The easy incorporation of $\mathrm{Fe}$ and $\mathrm{Mg}$ ions into a same framework is possibly due to the fact that the ionic radius of $\mathrm{Mg}^{2+}(66 \mathrm{pm})$ and $\mathrm{Fe}^{3+}(64 \mathrm{pm})$ ions in octahedral coordination modes are quite similar [19]. It should be noted that the real molar ratio of $\mathrm{Fe} / \mathrm{Mg}$ in the final products can be well controlled by simply modulating the concentration of metallic precursors in the reaction 
system. As determined precisely by inductively coupled plasma optical emission spectrometer (ICP-OES) analysis, the actual atomic ratios of $\mathrm{Fe}$ to $\mathrm{Mg}$ in the products are found to $4.50: 1,1.22: 1$ and $1: 1.69$ for $\mathrm{Fe} / \mathrm{Mg}-\mathrm{MIL}-$ 88B(2), Fe/Mg-MIL-88B(1) and Fe/Mg-MIL-88B(0.5) respectively, higher than those in the original starting materials. Accordingly, it can be concluded that the incorporation of $\mathrm{Fe}$ is more favourable than that of $\mathrm{Mg}$ in the resultant Fe/Mg-MIL-88B(n) frameworks. The reason behind the deviation between the theoretical and real molar ratios of $\mathrm{Fe}$ to $\mathrm{Mg}$ might be ascribed to the difference in the chemical reactivity of $\mathrm{Fe}(\mathrm{III})$ and $\mathrm{Mg}$ (II) cations, such as the divergence of their acidity and metal-ligand bond lability [20, 21]. Similarly, Lisa J. Wang and coworkers found that the final amounts of metal ions within the mixedmetal MOFs were mainly affected by the solubility, coordination modes of metal ions and $\mathrm{pH}$ of the reaction mixture [22]. In contrast, pure $\mathrm{Mg}-\mathrm{MOF}$ materials are fabricated via a similar hydrothermal reaction using $\mathrm{H}_{2} \mathrm{BDC}$ and $\mathrm{Mg}\left(\mathrm{NO}_{3}\right)_{2} \cdot 6 \mathrm{H}_{2} \mathrm{O}$ instead of $\mathrm{FeCl}_{3} \cdot 6 \mathrm{H}_{2} \mathrm{O}$. As a consequence, Mg-MOF displays a totally different morphology (Fig. S2), i.e. irregular granules with an average size of ca. $100 \mathrm{~nm}$. It should be noted that Mg-MOFs are extremely instable in aqueous medium, limiting their application in water treatment as absorbents. 

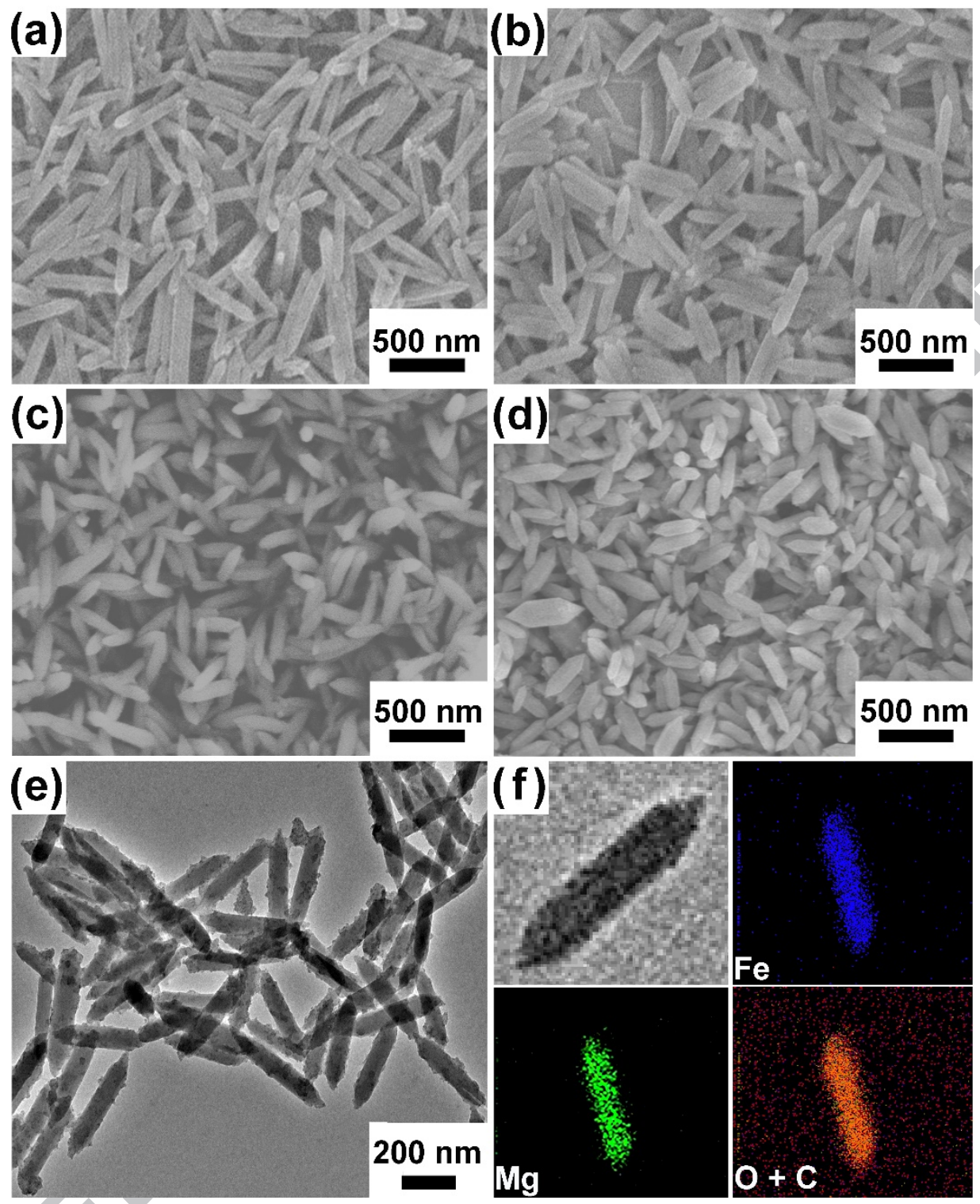

Fig. 1. (a-d) FESEM images of various samples: (a) Fe-MOF, (b) Fe/Mg-MIL-88B(2), (c) Fe/MgMIL-88B(1) (d) Fe/Mg-MIL-88B(0.5); (e, f) TEM image and corresponding EDX mapping of Fe/Mg-MIL-88B(0.5).

Besides their morphologies and compositional information, the crystallization behaviours of the resulting Fe/Mg-MIL-88B(n) with different $\mathrm{Fe} / \mathrm{Mg}$ molar ratios are investigated using X-ray diffraction (XRD) analyses. Meanwhile, XRD patterns of pure Fe-MIL-88B and Mg-MOFs are also provided as comparison [3,23]. As revealed by Fig. 2a, all patterns display sharp and prominent peaks, indicating high crystallinity of the as-synthesized MOFs. Note that the peak positions of the bimetallic Fe/Mg-MIL-88B(n) nanospindles are quite analogous to that of pure Fe-MIL-88B rather than Mg- 
MOFs, despite some slight discrepancies in their intensity, suggesting the bimetallic Fe/Mg-MIL-88B(n) possess the identical framework topology with respect to Fe-MIL-88B. In addition, there are only a single set of diffraction profiles for the as-obtained bimetallic Fe/Mg-MIL-88B(n) architectures, indicating the successful incorporation of two different central metal ions into a same framework [24]. From the magnified views in low angles (Fig. 2b), the diffraction peak at around $9.8^{\circ}$ slightly shifts toward a higher degree with the decreasing $\mathrm{Fe} / \mathrm{Mg}$ molar ratio; while an opposite tendency is noticed for the peak at ca. $10.8^{\circ}$, i.e., a clear shift toward a lower angle, further supporting the incorporation of $\mathrm{Mg}$ in the as-synthesized Fe/Mg-MIL-88B(n) architectures. Noteworthy, the differences in characteristic diffraction peak positions might be ascribed to the introduction of the second metals in the as-synthesized bimetallic Fe/Mg-MIL-88B(n) architectures. This observation is typically consistent with the previous reports, in which the simultaneous shifts in both directions (to lower and higher angles) are typically observed as a result of the flexibility or breathing effect of MIL-88B structures [16,25-28]. Correspondently, the shifts of diffraction peaks may cause the variation of the unit cell parameters and the unit cell volume of the resulting MOFs [28, 29]. Based on the Rietveld refinement results of Fe-MIL-88B and Fe/Mg-MIL88B(n) (Fig. S3), the details of the unit-cell parameters and cell volumes of the pure Fe-MIL-88B(n) are summarized in Table S1. Obviously, the increase of the cell parameter a and the decrease of cell parameter c simultaneously occur with the decreasing $\mathrm{Fe} / \mathrm{Mg}$ molar ratios, accompanied by the synchronous turbulence of the cell volumes. In spite of the changes of the lattice parameters, the underlying framework structure of the MOF crystals still remains intact. 

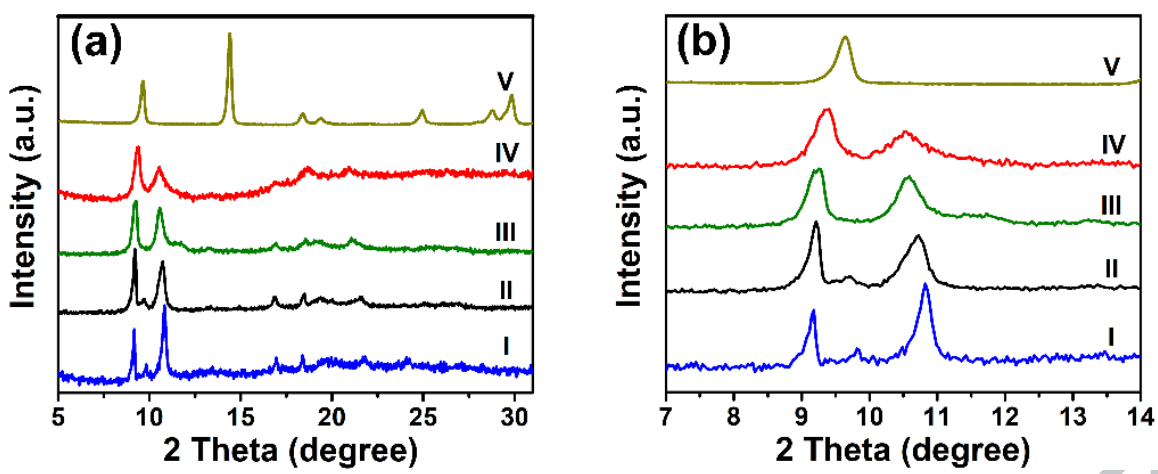

Fig. 2. (a) XRD patterns and magnified patterns (b) of various samples: (I) Fe-MIL-88B; (II) Fe/Mg-MIL-88B(2); (III) Fe/Mg-MIL-88B(1); (IV) Fe/Mg-MIL-88B(0.5); (V) MgMOFs.

The specific surface areas and porosity of the resulting MOF materials are further explored by nitrogen adsorption/desorption analyses at $77 \mathrm{~K}$. As displayed in Fig. 3a, all the samples exhibit the typical type I isotherms, indicative of the presence of a large amount of micropores. The BrunauerEmmett-Teller (BET) surface areas of the as-synthesized Fe/Mg-MIL-88B(2), Fe/Mg-MIL-88B(1) and Fe/Mg-MIL-88B(0.5) are determined to 218, 282 and $360 \mathrm{~m}^{2} / \mathrm{g}$, respectively. It is notable that the BET surface areas of the bimetallic $\mathrm{Fe} / \mathrm{Mg}-\mathrm{MIL}-88 \mathrm{~B}(\mathrm{n})$ architectures are markedly higher than that of the parent Fe-MIL-88B crystals $\left(57 \mathrm{~m}^{2} \mathrm{~g}^{-1}\right)$, implying that the introduction of $\mathrm{Mg}$ in MIL$88 \mathrm{~B}$ framework is conducive to promote the sufficient exposure of active sites of the resulting bimetallic $\mathrm{Fe} / \mathrm{Mg}-\mathrm{MIL}-88 \mathrm{~B}(\mathrm{n})$. Furthermore, as the $\mathrm{Mg} / \mathrm{Fe}$ molar ratio increases, the specific surface area and pore volume increase accordingly. This trend is consistent with the previously reported $\mathrm{Mg} / \mathrm{Ni}-\mathrm{MOF}$ 74, in which heavier transition metal substitution may lead to a reduction in BET surface area [30]. Thus, the more amounts of the incorporated light metal $(\mathrm{Mg})$ in the bimetallic Fe/Mg-MIL-88B(n), the larger the corresponding specific surface areas are. Aside from the crystalline structure and morphology as well as surface area, the chemical composition of the resulting bimetallic Fe/Mg-MIL-88B(n) plays a key role in determining of their thermal stability. The thermal stability of the bimetallic Fe/Mg-MIL-88B(n) increase as the $\mathrm{Mg}$ 
content increases, as evidenced by the gradual rise about the onset decomposition temperature of framework (Fig. 3b). The intriguing structural and compositional advantages, large surface area as well as high thermal stability of the bimetallic Fe/Mg-MIL-88B(n) architectures stimulate us to further evaluate their potential decontaminant performance toward $\operatorname{As}(\mathrm{V})$ as high efficient absorbents.
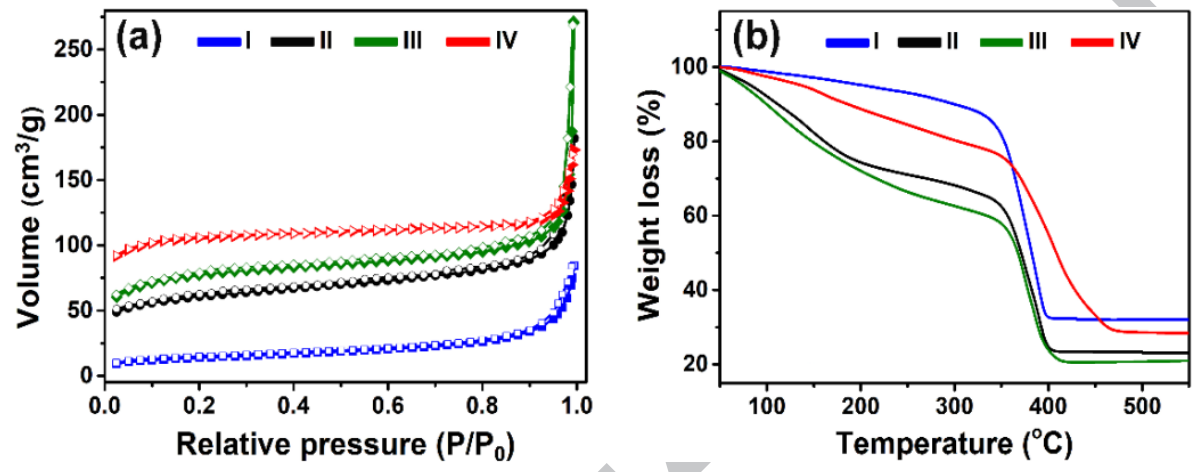

Fig. 3. $\mathrm{N}_{2}$ adsorption-desorption isotherms and thermal stability of various samples: (I) FeMIL-88B; (II) Fe/Mg-MIL-88B(2); (III) Fe/Mg-MIL-88B(1); (IV) Fe/Mg-MIL-88B(0.5).

\subsection{Sorption isotherm and sorption kinetics}

The equilibrium adsorption capacities of $\mathrm{As}(\mathrm{V})$ on the single-metallic Fe-MIL88B and bimetallic Fe/Mg-MIL-88B(n) materials can be illustrated by changing initial As(V) concentrations. It should be noted that Mg-MOF is unstable and degraded when exposed to water media as predicted, thus unsuitable for $\mathrm{As}(\mathrm{V})$ uptake. Both Langmuir and Freundlich models are utilized to analyze the sorption capacity of $\mathrm{As}(\mathrm{V})$ on various absorbents. As a consequence, the experimental data together with the corresponding fitting curves are plotted in Fig. 4 and the relative parameters are summarized in Table S2. Higher correlation coefficients $\left(\mathrm{R}^{2}\right)$ from Langmuir model as compared to the Freundlich model indicate a monolayer adsorption mechanism. As shown in Fig. 4, for all the absorbents, the adsorption capacities increase with increasing $\mathrm{As}(\mathrm{V})$ concentration and then gradually reach a plateau. Relatively low adsorption capacity for $\mathrm{As}(\mathrm{V})$ is obtained on the pristine Fe-MIL-88B, while the bimetallic Fe/Mg-MIL-88B(n) materials demonstrate the enhanced sorption capacity after the introduction of $\mathrm{Mg}$. Furthermore, the adsorption capacity of the as-obtained 
bimetallic Fe/Mg-MIL-88B(n) toward $\mathrm{As}(\mathrm{V})$ can be optimized by tuning the molar ratio of $\mathrm{Fe} / \mathrm{Mg}$, proportional to their surface areas. Specifically, the bimetallic Fe/MgMIL-88B(0.5) exhibits the highest uptake capacity of as high as $303.6 \mathrm{mg} \mathrm{g}^{-1}$ for $\mathrm{As}(\mathrm{V})$, which is far beyond that of the previously reported arsenate adsorbents listed in Table 1, including other analogous Fe-based MOFs materials.

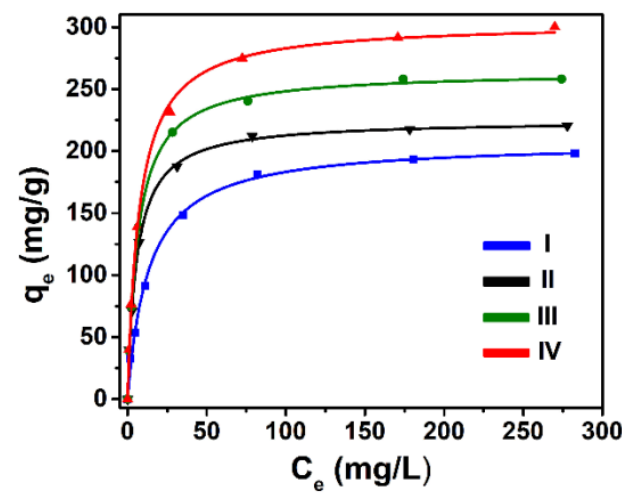

Fig. 4. Adsorption isotherms of various absorbents: (I) Fe-MIL-88B; (II) Fe/Mg-MIL88B(2); (III) Fe/Mg-MIL-88B(1); (IV) Fe/Mg-MIL-88B(0.5). (The dosage of the adsorbents: $0.2 \mathrm{~g} / \mathrm{L}, \mathrm{T}=25^{\circ} \mathrm{C}, \mathrm{t}=24 \mathrm{~h}$ ).

Table 1. Adsorption capacities of different adsorbents toward arsenate species.

\begin{tabular}{llll} 
Adsorbents & $\begin{array}{l}\text { Adsorption capacity } \\
\left(\mathrm{mg} \mathrm{g}^{-1}\right)\end{array}$ & $\mathrm{pH}$ & Ref. \\
\hline $\mathrm{MIL}-53(\mathrm{Fe})$ & 21.27 & 5 & {$[10]$} \\
$\mathrm{MIL}-100(\mathrm{Fe})$ & 110 & - & {$[9]$} \\
$\mathrm{Fe}-\mathrm{BTC}$ & 12.29 & 4 & {$[8]$} \\
$\mathrm{Fe}_{3} \mathrm{O}_{4} @ \mathrm{MIL}-101(\mathrm{Cr})$ & 80 & 7 & {$[31]$} \\
$\mathrm{MIL}-88 \mathrm{~B}(\mathrm{Fe})$ & 156.70 & 6 & {$[11]$} \\
$\mathrm{Mg}-\mathrm{Fe} \mathrm{LDH}$ & 129 & 5.5 & {$[32]$} \\
$\mathrm{ZIF-8}$ & 90.92 & - & {$[33]$} \\
Chitosan based electrospun & 30 & $4.3-4.6$ & {$[34]$} \\
nanofiber membrane & 150 & - & {$[35]$} \\
Cationic polymer-TiO & & 2 & {$[36]$} \\
Cellulose@iron oxide nanoparticles & 32.11 & 7 & {$[37]$} \\
TiO ${ }_{2}$-CNT & 18.2 & 7 & This work \\
Fe/Mg-MIL-88B(0.5) & 303.6 & &
\end{tabular}

After demonstrating the arsenate uptake capacities, the removal kinetics of As(V) on various absorbents are also evaluated to further demonstrate the advantages of bimetallic Fe/Mg-MIL-88B(n) materials. Fig. 5a displays the time-dependence of $\mathrm{As}(\mathrm{V})$ removal with $10 \mathrm{ppm}$ of initial concentration and 
$0.2 \mathrm{~g} \mathrm{~L}^{-1}$ of the absorbent dosage. For the monometallic Fe-MOF, a rather slow $\mathrm{As}(\mathrm{V})$ removal occurs and then reaches the equilibrium value within $60 \mathrm{~min}$. In contrast, the uptake rates of $\mathrm{As}(\mathrm{V})$ on the bimetallic Fe/Mg-MIL-88B(n) materials are considerably fast in the first $30 \mathrm{~min}$. Significantly, the removal efficiency increases with decreasing molar ratio of $\mathrm{Fe} / \mathrm{Mg}$ in the resulting bimetallic Fe/Mg-MIL-88B(n) when exposed to the same initial arsenate concentration. Typically, Fe/Mg-MIL-88B(0.5) demonstrates almost $97 \%$ of the As(V) removal efficiency. To describe the adsorption process quantitatively, the sorption kinetics data are subjected to pseudo second-order kinetics fitting. Accordingly, the linear relationships between $t / q_{t}$ ant $t$ are given in Fig. $5 b$ and the adsorption rate constants $\left(\mathrm{k}_{2}\right)$ calculated from the slopes and intercepts are summarized in Table S3. The considerable good linearity with high correlation coefficients $\left(\mathrm{R}^{2}=0.99\right)$ suggests a typical chemical sorption process in our case. These findings reveal that the bimetallic Fe/Mg-MIL-88B(n) materials possess the enhanced uptake performance toward $\mathrm{As}(\mathrm{V})$ in terms of high sorption capacity and fast sorption process as compared to the monometallic analogous Fe-MIL-88B, highlighting the significance of the composition modulation of the bimetallic Fe/Mg-MIL-88B(n) in boosting the As(V) uptake performance.
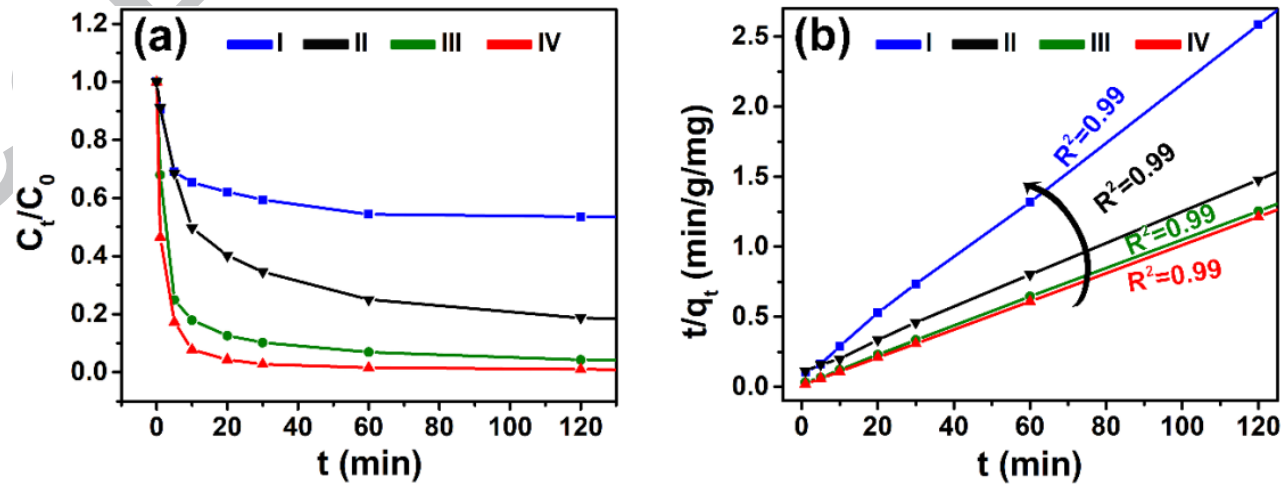

Fig. 5. (a) Adsorption kinetics of various samples: (I) Fe-MIL-88B; (II) Fe/Mg-MIL-88B(2); (III) Fe/Mg-MIL-88B(1); (IV) Fe/Mg-MIL-88B(0.5); (b) Pseudo-second order kinetic model fitting. (Initial As(V) concentration: $10 \mathrm{mg} / \mathrm{L}$, the dosage of the adsorbents: $0.2 \mathrm{~g} / \mathrm{L}, \mathrm{T}=25^{\circ} \mathrm{C}$ ).

\subsection{Influence of initial $p H$ on arsenate sorption}


It is well established that the solution $\mathrm{pH}$ value is one of the key operating factors in practical water treatment. To identify the optimum $\mathrm{pH}$ for the As(V) uptake, the effect of $\mathrm{pH}$ on the removal efficiency of $\mathrm{As}(\mathrm{V})$ is examined in the range of $2-12$, in which the optimized Fe/Mg-MIL- $88 \mathrm{~B}(0.5)$ is chosen as a representative absorbent with the initial arsenate concentration of $10 \mathrm{ppm}$. As displayed in Fig. 6, the investigated bimetallic Fe/Mg-MIL-88B(0.5) adsorbent demonstrates an outstanding arsenate decontamination performance (more than $95 \%$ of uptake efficiency) across a very broad $\mathrm{pH}$ range of 4 to 10 . Even if under very acidic $(\mathrm{pH} 2.0)$ or strong basic ( $\mathrm{pH}$ 12) conditions, the removal efficiency of $\mathrm{As}(\mathrm{V})$ still maintains around $75 \%$. In addition, the variation of the final (equilibrium) $\mathrm{pH}$ as a function of initial $\mathrm{pH}$ is also examined. As displayed in Fig. 6, the final $\mathrm{pH}$ is lower than that before $\mathrm{As}(\mathrm{V})$ adsorption when initial $\mathrm{pH}$ changes from 6 to 12, indicative of ligand-exchange mechanism during the arsenate adsorption process. These findings prefigure that the as-fabricated adsorbents possess a wide $\mathrm{pH}$ working range and outstanding removal capability toward $\mathrm{As}(\mathrm{V})$, facilitating the $\mathrm{As}(\mathrm{V})$ remediation in the most natural contaminated water normally with a $\mathrm{pH}$ condition of $6-8.5$.

To better understand the relationship between solution $\mathrm{pH}$ and arsenate uptake performance, the zeta potentials of the bimetallic Fe/Mg-MIL-88B(n) with various $\mathrm{Fe} / \mathrm{Mg}$ feeding ratios are measured under varying solution $\mathrm{pH}$ since the surface charge property is also a vital factor that affects the sorption capacity of an adsorbent. As illustrated in Fig. S4, the point of zero charge $\left(\mathrm{pH}_{\mathrm{zpc}}\right)$ of the pristine Fe-MIL-88B is identified to 5.89; while the $\mathrm{pH}_{\mathrm{zpc}}$ values of the three representative bimetallic Fe/MgMIL-88B(n) have an obvious red-shift from $6.29,6.37$ to 6.65 with increasing Fe/Mg feeding ratio. It is well known that a material with high $\mathrm{pH}_{\mathrm{zpc}}$ tends to become hydroxylated and thus shows strong sorption capability to negatively charged species. Such an enhanced positively charged surface of the bimetallic Fe/Mg-MIL-88B(n), especially under weak acidic and nearly neutral conditions, provides more opportunity for binding the negative charged $\mathrm{As}(\mathrm{V})$ ions through electrostatic interactions. Hence, the greatly increased sorption capacity of bimetallic Fe/Mg-MIL-88B(n) toward 
$\operatorname{As}(\mathrm{V})$ is not only attributed to the increase of specific surface areas but also to the change in surface properties.

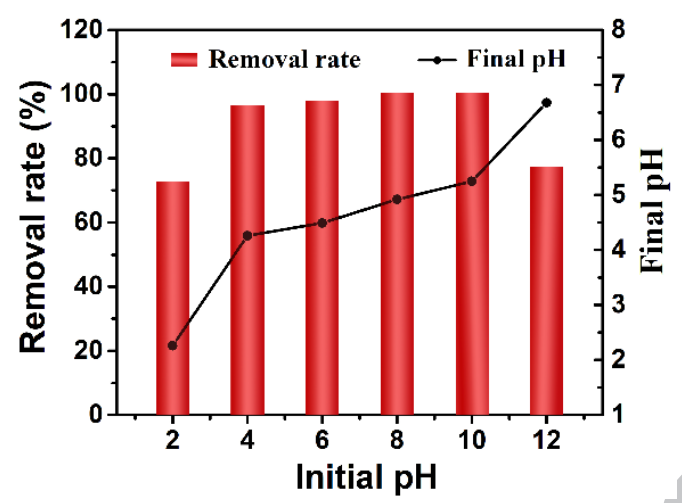

Fig. 6. Effect of initial $\mathrm{pH}$ on the removal rate of As (V) (II); dependent relationship between initial and final $\mathrm{pH}(\bullet)$. (Initial $\mathrm{As}(\mathrm{V})$ concentration: $10 \mathrm{mg} / \mathrm{L}$; the dosage of the adsorbent: $0.2 \mathrm{~g} / \mathrm{L}$ ).

\subsection{Influence of coexisting species on arsenate sorption}

Taking into account the complexity of natural water and industrial wastewater [38], it is highly desirable to investigate the influence of different interfering species toward on the uptake of $A s(V)$, which might compete for the binding sites available with arsenate and thus inhibit the removal of arsenate by varying the surface charges on the adsorbent. In this study, interfering experiments are carried out by monitoring variations of arsenate removal efficiency in the presence of the coexisting species at two different concentrations, in which the initial concentration of arsenate is $10 \mathrm{ppm}$ and the dosage of the representative bimetallic Fe/Mg-MIL- $88 \mathrm{~B}(0.5)$ is set as $0.2 \mathrm{~g} / \mathrm{L}$. As demonstrated in Fig. 7, the presence of $\mathrm{NO}_{3}^{-}, \mathrm{Cl}^{-}$and $\mathrm{SO}_{4}{ }^{2-}$, even at very high concentrations (75-fold as $0.01 \mathrm{M}$ and 750-fold as $0.1 \mathrm{M}$ ) compared with that of arsenate, does not have any significant influence on the removal of $\mathrm{As}(\mathrm{V})$. Notably, there is almost no obvious alteration in the removal efficiency of $\mathrm{As}(\mathrm{V})$ even when the concentration of coexisting anions $\left(\mathrm{Mg}^{2+}\right.$ and $\left.\mathrm{Ca}^{2+}\right)$ increases from 0.001 to $0.01 \mathrm{M}$, suggesting the strong sorption selectivity of the concerned absorbent toward arsenate over other competitive ions. It is noteworthy that NOM (e.g. HA and FA) at the level of up to $50 \mathrm{mg} \mathrm{C} / \mathrm{L}$ does 
not cause any obvious impact in the removal percentage of arsenate. Nevertheless, the removal efficiency of arsenate reduces greatly (28\%) when high concentration of $\mathrm{HCO}_{3}^{-}(0.1 \mathrm{M})$ is involved; Meanwhile it occurs $10 \%$ of decrease in the removal rates of arsenate under $0.01 \mathrm{M}$ of $\mathrm{HCO}_{3}^{-}$. The behaviour can be attributed to higher $\mathrm{pH}(8.9)$ in $0.1 \mathrm{M}$ of $\mathrm{HCO}_{3}{ }^{-}$solution, in which a large amount of $\mathrm{OH}^{-}$may compete with arsenate for the identical sorption sites on given adsorbents. Similarly, the presence of silicate also causes the adverse interference ( 85.2 and $62.7 \%$ of removal efficiency for 0.01 and $0.1 \mathrm{M}$ of $\mathrm{SiO}_{3}{ }^{2-}$, respectively) towards $\mathrm{As}(\mathrm{V})$ removal to some extent. Likewise, there is a significant depression in the arsenate uptake when phosphate at the levels of 0.1 and $0.01 \mathrm{M}$ is introduced, as reflected by the removal efficiency of $78.5 \%$ and $47.7 \%$, respectively, which can be ascribed to the chemical similarity between arsenate and phosphate. Taking into account the fact that the concentrations of $\mathrm{HCO}_{3}^{-}$and $\mathrm{SiO}_{3}^{-}$in most natural environmental waters lie in the range of $0.31-18.36 \mathrm{mM}, 0.013-0.395 \mathrm{mM}$, respectively [39-41]; while the level of $\mathrm{PO}_{4}{ }^{3-}$ is usually much less than $1 \mathrm{ppm}$ $(0.01 \mathrm{mM})$ [42], hence, the inhibiting effects from these potentially competitive species on the arsenate adsorption will be basically neglected. These findings indicate strong anti-interference ability of the developed bimetallic Fe/MgMIL-88B(0.5) absorbent and preferable affinity for arsenate over the coexisting interferents mentioned above, prefiguring their feasibility for the exceptional arsenate decontamination in the complex environmental system.

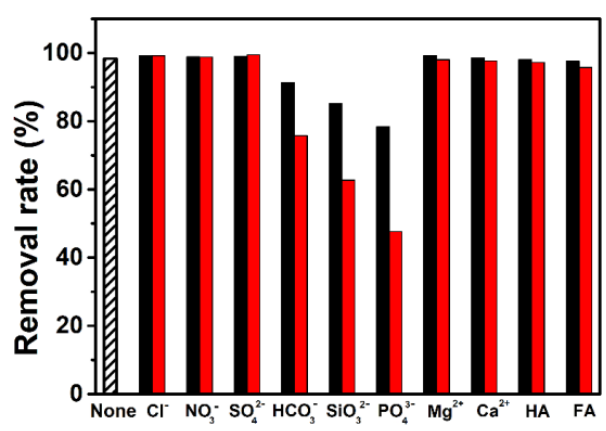


Fig. 7. Effect of coexisting ions and NOM on the removal efficiency of arsenate on Fe/MgMIL-88B(0.5). (Initial As(V) concentration: $10 \mathrm{mg} / \mathrm{L}$; the dosage of the adsorbent: $0.2 \mathrm{~g} / \mathrm{L}$; the concentrations of $\mathrm{Cl}^{-}, \mathrm{NO}_{3}^{-}, \mathrm{SO}_{4}^{-}$and $\mathrm{HCO}_{3}^{-}: 0.01$ or $0.1 \mathrm{M}$; the concentrations of $\mathrm{Mg}^{2+}$ and $\mathrm{Ca}^{2+}: 0.001$ or $0.01 \mathrm{M}$; the concentrations of HA and FA: 10 or $50 \mathrm{mg} \mathrm{C} / \mathrm{L}$ ).

\subsection{Stability and Recyclability of Fe/Mg-MIL-88B(0.5)}

As we know, excellent regeneration and structural stability are the prerequisite for ensuring the possible sustainable application of a given absorbent. To assess the stability of the bimetallic Fe/Mg-MIL- $88 \mathrm{~B}(0.5)$ adsorbents, the samples saturated with arsenate are collected and subjected to XRD characterization. As displayed in Fig. S5, the main XRD peaks match well with the pristine Fe/Mg-MIL-88B(0.5), suggesting that no new phase comes into being. Meanwhile, SEM and TEM observations (Fig. S6) also provide a clear evidence that Fe/Mg-MIL-88B(0.5) after arsenate treatment still remains intact hexagonal rod-like morphology, revealing no damage of the crystal structure throughout the adsorption test. Besides, it can be observed from EDS mapping that iron, magnesium and arsenic elements are well distributed in the entire region of needle-like nanorods, verifying the uniform incorporation of arsenic species within the bimetallic Fe/Mg-MIL-88B(0.5) adsorbents. Importantly, after arsenate treatment, no iron or magnesium ions are detected in the filtrates based on ICP measurement, further confirming the excellent stability of the resulting Fe/Mg-MIL-88B(0.5).

In order to investigate the reusability of the bimetallic Fe/Mg-MIL$88 \mathrm{~B}(0.5)$ adsorbent, a regeneration experiment is carried out by treating the As(V)-loaded absorbent with 0.01 M nitric acid solution [9]. As displayed in Fig. 8 , it still maintains $84 \%$ of the arsenate removal efficiency even after five adsorption-desorption rounds, indicating that the investigated adsorbents have an excellent reusability in $\mathrm{As}(\mathrm{V})$ sequestration. In view of high adsorption capacity, broad $\mathrm{pH}$ applicable range and excellent structural stability as well as exceptional reusability, it can be reasonably surmised that the proposed 
bimetallic Fe/Mg-MIL-88B(0.5) adsorbents will possess great promise in sustainable arsenic remediation.

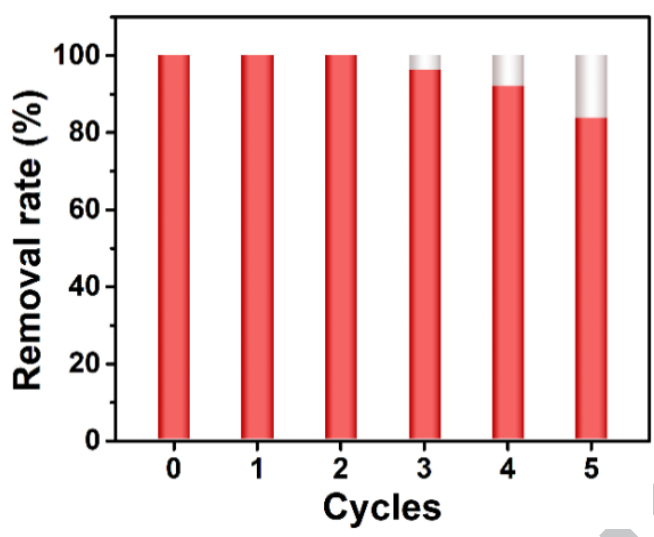

Fig. 8. Removal rate of $\mathrm{As}(\mathrm{V})$ on $\mathrm{Fe} / \mathrm{Mg}-\mathrm{MIL}-88 \mathrm{~B}(0.5)$ under different regeneration cycles (initial As(v) $=10 \mathrm{ppm}$, adsorbent dose $0.2 \mathrm{~g} \mathrm{~L}^{-1}$ ).

\subsection{Natural water treatment}

As a demonstration, we explored the feasibility of the proposed bimetallic $\mathrm{Fe} / \mathrm{Mg}-\mathrm{MIL}-88 \mathrm{~B}(0.5)$ absorbent for the arsenic treatment in natural lake water. Here, Dongpu Reservoir water (Hefei city, China) is selected as the representative real environmental sample and the relevant water quality data, including the coexisting anions, cations, DOC and $\mathrm{pH}$, are given in Table S4. Since the arsenic concentration in the selected water is lower than the detection limit of ICP-MS analysis, based on the previously reported arsenic concentrations in most arsenic-contaminated waters, trace level of As(V) standard solution $(0.5 \mathrm{ppm})$ are purposely spiked to the sampled solution mentioned above. It should be noted that the water samples are untreated and directly used throughout the adsorption experiments, in which the optimized $\mathrm{Fe} / \mathrm{Mg}-\mathrm{MIL}-88 \mathrm{~B}(0.5)$ is selected as a representative absorbent. Upon the injection of $0.01 \mathrm{~g} / \mathrm{L}$ of the absorbent (Fig. 9), the removal efficiency of As(V) increases rapidly and reaches the sorption equilibrium within $15 \mathrm{~min}$, accompanied by $98.4 \%$ the removal rate. Remarkably, it takes only 5 min to achieve $99.6 \%$ of the removal rate when the dosage of the absorbent upgrades to $0.05 \mathrm{~g} / \mathrm{L}$. It is noteworthy that the residual arsenic concentrations at the 
equilibrium are below the permissive threshold value (10 ppb) in drinking water recommended by WHO regardless of the dosages of 0.01 or $0.05 \mathrm{~g} / \mathrm{L}$. The ultrafast and highly efficient sequestration of $\mathrm{As}(\mathrm{V})$ further confirm applicability of the developed bimetallic Fe/Mg-MIL-88B(0.5) in realistic complicated environment water, prefiguring their great potential in the deep purification of arsenic-polluted water.

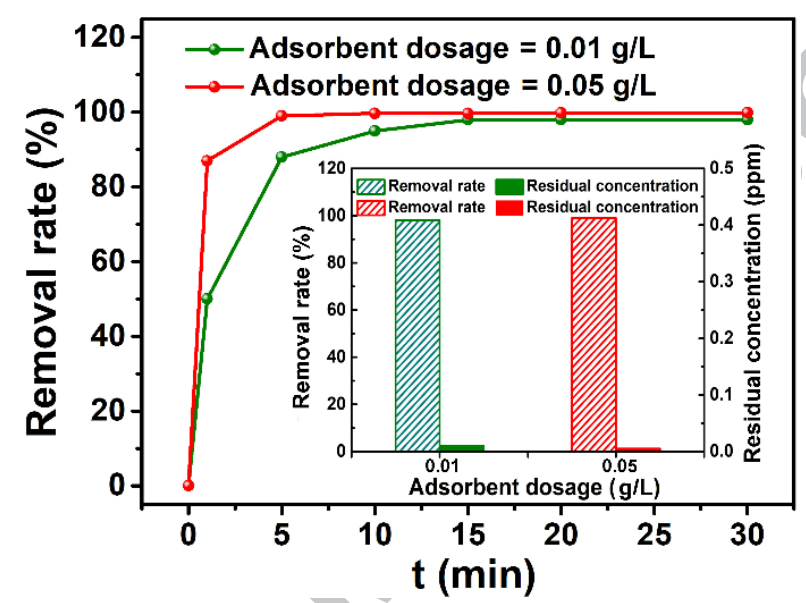

Fig. 9. Removal of arsenate from natural lake water spiked with $0.5 \mathrm{ppm}$ of As(V). (Experimental conditions: $\mathrm{V}_{\text {total }}=100 \mathrm{~mL}$; the dosage of adsorbent $=0.01$ or $0.05 \mathrm{~g} / \mathrm{L}$ ).

\subsection{Sorption mechanism of arsenate on the bimetallic Fe/Mg-MIL-88B(0.5)}

To gain insight into the sorption mechanism of arsenate on the bimetallic Fe/Mg-MIL-88B(0.5), FT-IR measurements are firstly conducted for the variation of surface functional groups before and after As(V) treatment. As for the pristine bimetallic Fe/Mg-MIL-88B(0.5) (Fig. 10a), two characteristic bands around 1579 and $1392 \mathrm{~cm}^{-1}$ are assigned to $\mathrm{O}-\mathrm{C}=\mathrm{O}$ symmetric and asymmetric stretching vibrations of organic ligands [43]. Additionally, the small band around $1504 \mathrm{~cm}^{-1}$ is ascribed to $\mathrm{C}=\mathrm{C}$ vibrational mode of the benzene ring [44]; while the bands at 750,821 and $881 \mathrm{~cm}^{-1}$ correspond to the $\mathrm{C}-\mathrm{H}$ vibrational modes of the benzene ring [45]. Meanwhile, the band at ca. $542 \mathrm{~cm}^{-1}$ can be attributed to the $\mathrm{Fe} / \mathrm{Mg}-\mathrm{O}$ bending vibration in the resulting bimetallic Fe/Mg-MIL-88B(0.5) [10,46]. The aforementioned functional groups not only reveal the successful coordination of the carboxylate groups of BDC 
linkers to metal ions [43], but also provide the solid support for the simultaneous incorporation of both $\mathrm{Fe}$ and $\mathrm{Mg}$ into the resulting framework. After being treated with As(V), several new peaks appear at 730, 782, and 825 $\mathrm{cm}^{-1}$, respectively, as compared to the pristine material. As reported, the band at near $730 \mathrm{~cm}^{-1}$ can be reasonably assigned to protonated As- $\mathrm{O}-\mathrm{H}$ bond of the adsorbed arsenate species [47]. In the meantime, the latter two are related to the formation of $\mathrm{Mg}-\mathrm{O}-\mathrm{As}$ bonds and $\mathrm{Fe}-\mathrm{O}-\mathrm{As}$ complexes $[32,9,48]$, respectively. Moreover, the $\mathrm{Fe} / \mathrm{Mg}-\mathrm{O}$ bond also shifts to the lower frequency from 542 to $525 \mathrm{~cm}^{-1}$, which can be attributed to the strong coordination between $\mathrm{Fe}(\mathrm{III}) / \mathrm{Mg}(\mathrm{II})$ and $\mathrm{As}(\mathrm{V})$ [49]. These findings mentioned above indicate that chemical adsorption is primarily responsible for the uptake of arsenate species, which is consistent with the former results from the sorption kinetics modeling.

In addition, XPS analyses provide further support for the underlying mechanism of $\mathrm{As}(\mathrm{V})$ sorption on the as-obtained absorbents. As demonstrated in Fig. 10b, the survey spectra reveal the existence of $\mathrm{Fe}, \mathrm{Mg}, \mathrm{O}$ and $\mathrm{C}$ elements within the obtained bimetallic Fe/Mg-MIL-88B(0.5). After arsenate treatment, several new peaks appear at around $1327 \mathrm{eV}, 147 \mathrm{eV}, 261 \mathrm{eV}$ and 46 $\mathrm{eV}$, corresponding to As 2p, As 3p, As Auger and As 3d peak, respectively, indicating the successful immobilization of arsenic species on the surface of $\mathrm{Fe} / \mathrm{Mg}-\mathrm{MIL}-88 \mathrm{~B}(0.5)$ absorbent $[9,35]$. It is noteworthy that Fe $2 \mathrm{p}$ spectrum shifts slightly toward high binding energy (ca. $0.26 \mathrm{eV}$ ); Meanwhile, Mg KLL Auger peak also displays a similarly positive shift $(0.22 \mathrm{eV})$, which reveals that both iron and magnesium are involved in the uptake of arsenate via the chemical interactions associated with the potential formation of $\mathrm{Fe} / \mathrm{Mg}-\mathrm{O}-\mathrm{As}$ bonds. In the O1s spectrum, two peaks at 531.7 and $532.78 \mathrm{eV}$ are related to the oxygen components on the carboxyl groups of BDC linker and the $\mathrm{Fe} / \mathrm{Mg}-\mathrm{O}$ bonds of MIL- $88 \mathrm{~B}(\mathrm{Fe})[8,10,50]$. After the adsorption of arsenate, a new peak appears at $531.0 \mathrm{eV}$, which can be ascribed to As-O bond [51]. In the meantime, the peak intensity of $\mathrm{Fe} / \mathrm{Mg}-\mathrm{O}$ weakens after $\mathrm{As}(\mathrm{V})$ sorption, which further verifies the formation of $\mathrm{Fe} / \mathrm{Mg}-\mathrm{O}-\mathrm{As}$ bond [51]. 

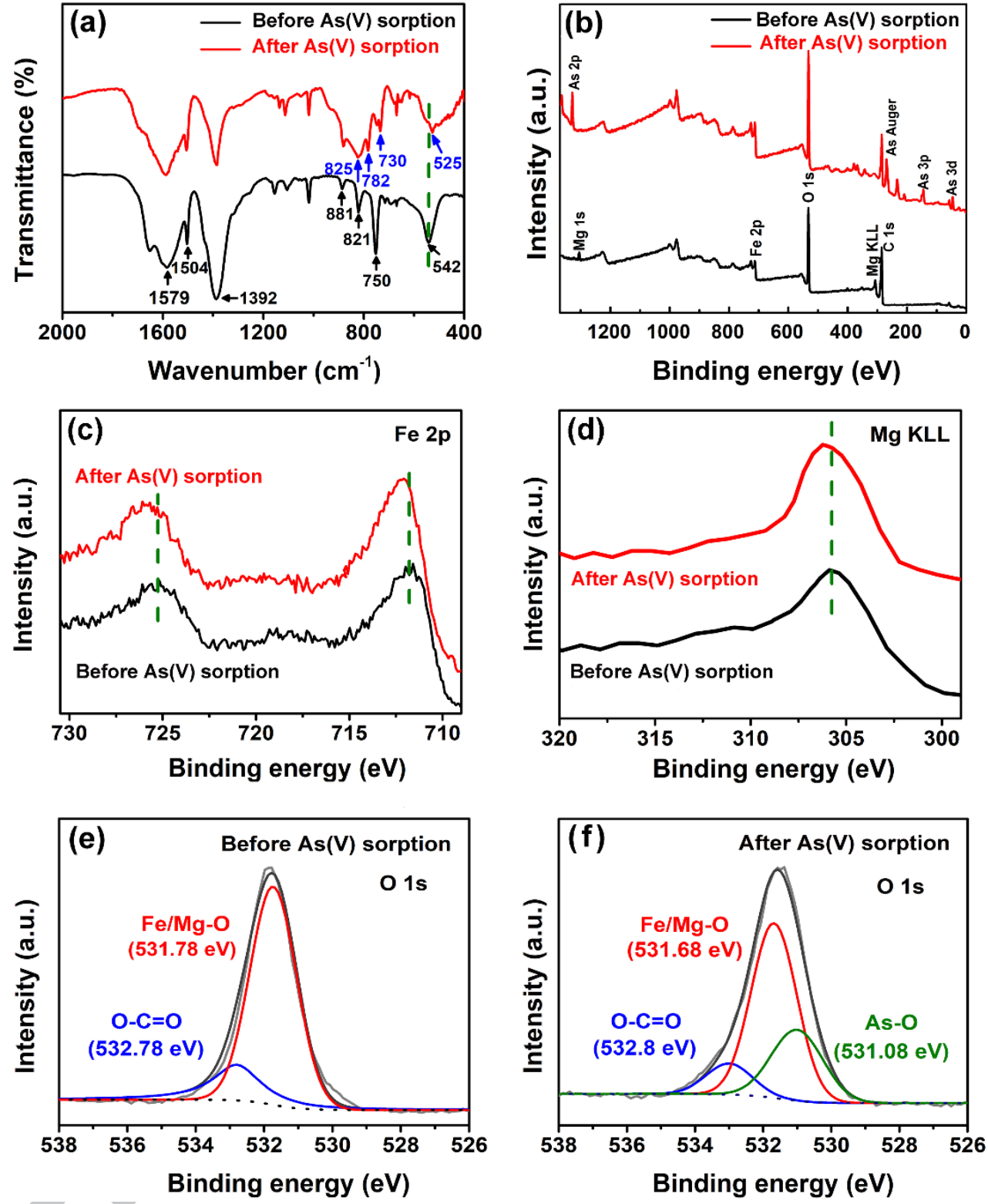

Fig. 10. FTIR spectra (a) and XPS spectra (b-f) of Fe/Mg-MIL-88B(0.5) before and after arsenate adsorption.

\section{Conclusion}

In summary, we have demonstrated an effective strategy to fabricate the bimetallic $\mathrm{Fe} / \mathrm{Mg}-\mathrm{MIL}-88 \mathrm{~B}(\mathrm{n})$ with diverse $\mathrm{Fe} / \mathrm{Mg}$ ratios by simply tuning the feeding amount of Fe to $\mathrm{Mg}$ precursors. The chemical compositions of the resulting bimetallic Fe/Mg-MIL-88B(n) are found to have a significant impact on their lattice structure, morphology, size and surface areas, accordingly playing important roles in the resultant performance modulation. As expected, the optimized bimetallic Fe/Mg-MIL- 
$88 \mathrm{~B}(0.5)$ exhibit the superior decontamination performance towards arsenate species, including remarkable uptake capacities, considerably fast sorption rates, broad $\mathrm{pH}$ working range, strong anti-interference, exceptional regeneration and structural stability as well as excellent cycling stability, suggesting their feasibility and great potential in the complex environmental water. To sum up, this study may not only offer novel insights in rationally designing the bimetallic MOFs with tunable structure and desirable functionalities, but also pave the way for their application in environmental pollutant remediation.

\section{Acknowledgements}

This work was financially supported by National Natural Science Foundation of China (Grants 51572263, 51772299, 51472246) and Strategic Priority Research Program of the Chinese Academy of Sciences (Grant XDA09030200).

\section{References}

[1] X. Ge, J.T. Liu, X.Y. Song, G.Z. Wang, H.M. Zhang, Y.X. Zhang, H.J. Zhao, Hierarchical iron containing $\gamma-\mathrm{MnO}_{2}$ hollow microspheres: a facile one-step synthesis and effective removal of As(III) via oxidation and adsorption, Chem. Eng. J. 301 (2016) 139-148.

[2] R. Singh, S. Singh, P. Parihar, V.P. Singh, S.M. Prasad, Arsenic contamination, consequences and remediation techniques: a review, Ecotoxicol. Environ. Saf. 112 (2015) 247-270.

[3] D.H. Xie, Y. Ma, Y. Gu, H.J. Zhou, H.M. Zhang, G.Z. Wang, Y.X. Zhang, H.J. Zhao, Bifunctional $\mathrm{NH}_{2}$-MIL-88(Fe) metal-organicframework nanooctahedra for highly sensitivedetection and efficient removal of arsenate in aqueous media, J. Mater. Chem. A 5 (2017) 23794-23804.

[4] D. Mohan, C.U. Pittman-Jr, Arsenic removal from water/wastewater using adsorbents--a critical review, J. Hazard. Mater. 142 (2007) 1-53. 
[5] S.W. Zhang, H.C. Yang, H.Y. Huang, H.H. Gao, X.X. Wang, R.Y. Cao, J.X. Li, X.J. Xu, X.K. Wang, Unexpected ultrafast and high adsorption capacity of oxygen vacancy-rich $\mathrm{WO}_{\mathrm{x}} / \mathrm{C}$ nanowire networks for aqueous $\mathrm{Pb}^{2+}$ and methylene blue removal, J. Mater. Chem. A 5 (2017) 15913-15922.

[6] S.W. Zhang, H.H. Gao, J.X. Li, Y.S. Huang, A. Alsaedi, T. Hayat, X.J. Xu, X.K. Wang, Rice husks as a sustainable silica source for hierarchical flower-like metal silicate architectures assembled into ultrathin nanosheets for adsorption and catalysis, J. Hazard. Mater. 321 (2017) 92-102.

[7] A.A. Alqadami, M. Naushad, Z.A. Alothman, A.A. Ghfar, Novel metalorganic framework (MOF) based composite material for the sequestration of $\mathrm{U}(\mathrm{VI})$ and Th(IV) metal ions from aqueous environment, ACS Appl. Mater. Interfaces 9 (2017) 36026-36037.

[8] B.J. Zhu, X.Y. Yu, Y. Jia, F.M. Peng, B. Sun, M.Y. Zhang, T. Luo, J. H. Liu, X.J. Huang, Iron and 1,3,5-benzenetricarboxylic metal-organic coordination polymers prepared by solvothermal method and their application in efficient As(V) removal from aqueous solutions, J. Phys. Chem. C 116 (2012) $8601-8607$.

[9] J.H. Cai, X.Y. Wang, Y. Zhou, L. Jiang, C.R. Wang, Selective adsorption of arsenate and the reversible structure transformation of the mesoporous metalorganic framework MIL-100(Fe), Chem. Chem. Phys. 18 (2016) $10864-10867$.

[10] T.A. Vu, G.H. Le, C.D. Dao, L.Q. Dang, K.T. Nguyen, Q.K. Nguyen, P.T. Dang, H.T.K. Tran, Q.T. Duong, T.V. Nguyen, G.D. Lee, Arsenic removal from aqueous solutions by adsorption using novel MIL-53(Fe) as a highly efficient adsorbent, RSC Adv. 287 (2015) 364-372.

[11] S. Hou, Y.N. Wu, L. Feng, W. Chen, Y. Wang, C. Morlay, F. Li, Green synthesis and evaluation of an iron-based metal-organic framework MIL-88B for efficient decontamination of arsenate from water, Dalton Trans. 47 (2018) $2222-2231$. 
[12] T.M. Becker, J. Heinen, D. Dubbeldam, L.C. Lin, T.J.H. Vlugt, Polarizable force fields for $\mathrm{CO}_{2}$ and $\mathrm{CH}_{4}$ adsorption in M-MOF-74, J. Phys. Chem. C 121 (2017) 4659-4673.

[13] C. H. Lau, R. Babarao, M. R. Hill, A route to drastic increase of $\mathrm{CO}_{2}$ uptake in $\mathrm{Zr}$ metal organic framework UiO-66, Chem. Commun. 49 (2013) $3634-3636$.

[14] G. Kaur, R.K. Rai, D. Tyagi, X. Yao, P.Z. Li, X.C. Yang, Y. Zhao, Q. Xu, S. K. Singh, Room-temperature synthesis of bimetallic Co- $\mathrm{Zn}$ based zeolitic imidazolate frameworks in water for enhanced $\mathrm{CO}_{2}$ and $\mathrm{H}_{2}$ uptakes, J. Mater. Chem. A 4 (2016) 14932-14938.

[15] G.T. Vuong, M.H. Pham, T.O. Do, Synthesis and engineering porosity of a mixed metal $\mathrm{Fe}_{2} \mathrm{Ni}$ MIL-88B metal-organic framework, Dalton Trans. 42 (2013) 550-557.

[16] M.H. Pham, G.T. Vuong, A.T. Vu, T.O. Do, Novel route to size-controlled Fe-MIL-88B-NH ${ }_{2}$ metal-organic framework nanocrystals, Langmuir 27 (2011) 15261-15267.

[17] S.A. Park, H.J. Lee, Y.J. Cho, S. Choi, M. Oh, Coordination polymer nanobamboos of $\left\{\mathrm{Fe}_{(\mathrm{x})} \mathrm{In}_{(1-\mathrm{x})}\right\}-\mathrm{MIL}-88 \mathrm{~B}$ : induced formation of a virtual InMIL-88B, Chem. Eur. J. 20 (2014) 5559-64.

[18] Z.J. Jiang, S. Cheng, H. Rong, Z. Jiang, J. Huang, General synthesis of $\mathrm{MFe}_{2} \mathrm{O}_{4} /$ carbon $(\mathrm{M}=\mathrm{Zn}, \mathrm{Mn}, \mathrm{Co}$, Ni) spindles from mixed metal organic frameworks as high performance anodes for lithium ion batteries, J. Mater. Chem. A 5 (2017) 23641-23650.

[19] P.A. Ciullo, Silicate Steuctures. Industrial minerals and their uses, (1996) $1-16$.

[20] J.D. Evans, C.J. Sumby, C.J. Doonan, Post-synthetic metalation of metalorganic frameworks, Chem. Soc. Rev. 43 (2014) 5933-5951.

[21] S. Wongsakulphasatch, F. Nouar, J. Rodriguez, L. Scott, G.C. Le, T. Devic, P. Horcajada, J.M. Greneche, P.L. Llewellyn, A. Vimont, G. Clet, M. Daturi, C. Serre, Direct accessibility of mixed-metal (III/II) acid sites through the 
rational synthesis of porous metal carboxylates, Chem. Commun. 51 (2015) 10194-10197.

[22] L.J. Wang, H. Deng, H. Furukawa, F. Gandara, K.E. Cordova, D. Peri, O.M. Yaghi, Synthesis and characterization of metal-organic framework-74 containing 2, 4, 6, 8, and 10 different metals, Inorg. Chem. 53 (2014) $5881-5883$.

[23] R.P. Davies, R.J. Less, P.D. Lickiss, A.J. White, Framework materials assembled from magnesium carboxylate building units, Dalton Trans. 24 (2007) 2528-35.

[24] H.F. Yao, Y. Yang, H. Liu, F. G. Xi, E.Q. Gao, CPO-27-M as heterogeneous catalysts for aldehyde cyanosilylation and styrene oxidation, J. Mol. Catal. A: Chem. 394 (2014) 57-65.

[25] M. Ma, A. Bétard, I. Weber, N.S. Al-Hokbany, R.A. Fischer, N.N. Metzler, Iron-based metal-organic frameworks $\mathrm{MIL}-88 \mathrm{~B}$ and $\mathrm{NH}_{2}$-MIL-88B: high quality microwave synthesis and solvent-induced lattice "breathing", Cryst. Growth Des. 13 (2013) 2286-2291.

[26] C. Scherb, A. Schdel, T. Bein, Directing the structure of metal-organic frameworks by oriented surface growth on an organic monolayer, Angew. Chem. Int. Ed. 47 (2008) 5777-5779.

[27] A.K. Singh, A.K. Singh, Synthesis and spectral characterization of trinuclear, oxo-centered, carboxylate-bridged, mixed-valence iron complexes with schiff Bases, Spectrochim. Acta, Part A 96 (2012)986-991.

[28] C. Serre, D.C. Mellot, S.A. Surblé, N. Y. Filinchuk, G. Férey, Role of solvent-host interactions that lead to very large swelling of hybrid frameworks, Science 315 (2007) 1828-1831.

[29] S. Choi, W. Cha, H. Ji, D. Kim, H.J. Lee, M. Oh, Synthesis of hybrid metalorganic frameworks of $\left\{\mathrm{Fe}_{\mathrm{x}} \mathrm{M}_{\mathrm{y}} \mathrm{M}_{1-\mathrm{x}-\mathrm{y}}\right\}-\mathrm{MIL}-88 \mathrm{~B}$ and the use of anions to control their structural features, Nanoscale 8 (2016) 16743-16751.

[30] Y. Jiao, C.R. Morelock, N.C. Burtch, W.P. Mounfield, J.T. Hungerford, K.S. Walton, Tuning the kinetic water stability and adsorption interactions of $\mathrm{Mg}$ - 
MOF-74 by partial substitution with Co or Ni, Ind. Eng. Chem. Res. 54 (2015) 12408-12414.

[31] K. Folens, K. Leus, N.R. Nicomel, M. Meledina, S. Turner, T.G. Van, G.D. Laing, V.D.P. Voort, $\mathrm{Fe}_{3} \mathrm{O}_{4} @$ MIL-101-A selective and regenerable adsorbent for the removal of as species from water, Eur. J. Inorg. Chem. 2016 (2016) 4395-4401.

[32] B. Hudcova, Sorption mechanisms of arsenate on $\mathrm{Mg}-\mathrm{Fe}$ layered double hydroxides: a combination of adsorption modeling and solid state analysis, Chemosphere 168 (2017) 539-548.

[33] Y.N. Wu, M. Zhou, B. Zhang, B. Wu, J. Li, J. Qiao, X. Guan, F. Li, Amino acid assisted templating synthesis of hierarchical zeolitic imidazolate framework-8 for efficient arsenate removal, Nanoscale 6 (2014) 1105-1112.

[34] L.L. Min, Z.H. Yuan, L.B. Zhong, Q. Liu, R.X. Wu, Y.M. Zheng, Preparation of chitosan based electrospun nanofiber membrane and its adsorptive removal of arsenate from aqueous solution, Chem. Eng. J. 267 (2015) 132-141.

[35] B.F. Urbano, I. Villenas, B.L. Rivas, C.H. Campos, Cationic polymer-TiO nanocomposite sorbent for arsenate removal, Chem. Eng. J. 268 (2015) 362370.

[36] X.L. Yu, S.R. Tong, M.F. Ge, J.C. Zuo, C.Y. Cao, W.G. Song, One-step synthesis of magnetic composites of cellulose@iron oxide nanoparticles for arsenic removal, J. Mater. Chem. A 1 (2013) 959-965.

[37] H. Liu, K. Zuo, C.D. Vecitis, Titanium dioxide-coated carbon nanotube network filter for rapid and effective arsenic sorption, Environ. Sci. Technol. 48 (2014) 13871-13879.

[38] S.W. Zhang, Q.H. Fan, H.H. Gao, Y.S. Huang, X. Liu, J.X. Li, X.J. Xu, X.K. Wang, Formation of $\mathrm{Fe}_{3} \mathrm{O}_{4} @ \mathrm{MnO}_{2}$ ball-in-ball hollow spheres as a high performance catalyst with enhanced catalytic performances, J. Mater. Chem. A 4 (2016) 1414-1422. 
[39] B. Zhang, X. Song, Y. Zhang, D. Han, C. Tang, Y. Yu, Y. Ma, Hydrochemical characteristics and water quality assessment of surface water and groundwater in songnen plain, Northeast China, Water Res. 46 (2012) $2737-48$.

[40] P. Li, J. Wu, H. Qian, Y. Zhang, N. Yang, L. Jing, P. Yu, Hydrogeochemical characterization of groundwater in and around a wastewater irrigated forest in the southeastern edge of the tengger desert, northwest China, Exposure and Health 8 (2016) 331-348.

[41] J.D. Hem, Study and interpretation of the chemical characteristics of natural water, Geological Survey (1989).

[42] F. Xie, F. Wu, G. Liu, Y. Mu, C. Feng, H. Wang, J.P. Giesy, Removal of phosphate from eutrophic lakes through adsorption by in situ formation of magnesium hydroxide from diatomite, Environ. Sci. Technol. 48 (2014) $582-90$.

[43] Y. Gu, D.H. Xie, Y. Ma, W.X. Qin, H.M. Zhang, G.Z. Wang, Y.X. Zhang, H.J. Zhao, Size modulation of zirconium-based metal organic frameworks for highly efficient phosphate remediation, ACS Appl. Mater. Interfaces 9 (2017) 32151-32160.

[44] X.Q. Xu, R.X. Liu, Y.H. Cui, X.X. Liang, C. Lei, S.Y. Meng, Y.L. Ma, Z.Q. Lei, Z.W. Yang, PANI/FeUiO-66 nanohybrids with enhanced visible-light promoted photocatalytic activity for the selectively aerobic oxidation of aromatic alcohols, Appl. Catal.B 210 (2017) 484-494.

[45] P.D.C. Dietzel, R. Blom, H. Fjellvåg, Base-induced formation of two magnesium metal-organic framework compounds with a bifunctional tetratopic ligand, Eur. J. Inorg. Chem. 2008 (2008) 3624-3632.

[46] T.R. Koodali, J.K. Kenneth, Solvent effects in the hydrolysis of magnesium methoxide, and the production of nanocrystalline magnesium hydroxide. An aid in understanding the formation of porous inorganic materials, Chem. Mater. 17 (2005) 65-73. 
[47] J.Y. Park, J. H Kim, Characterization of adsorbed Arsenate on amorphous and nano crystalline MgFe-layered double hydroxides, Nanopart. Res. 13 (2010) 887-894.

[48] J.F. Sui, L.H. Wang, W.R. Zhao, J.C. Hao, Iron-naphthalenedicarboxylic acid gels and their high efficiency in removing arsenic (V), Chem. Commun. 52 (2016) 6993-6996.

[49] Z. Hu, G. Tong, Z. Chen, X. Zhan, Z. Hu, Adsorption of roxarsone by iron (hydr)oxide-modified multiwalled carbon nanotubes from aqueous solution and its mechanisms, Int. J. Environ. Sci. Technol. 11 (2014) 785-794.

[50] X.H. Li, W.L. Guo, Z.H. Liu, R.Q. Wang, H. Liu, Fe-based MOFs for efficient adsorption and degradation of acid orange 7 in aqueous solution via persulfate activation, App. Surf. Sci. 369 (2016) 130-136.

[51] D.J. Kang, X.L. Yu, S.R. Tong, M.F. Ge, J.C. Zuo, C.Y. Cao, W.G. Song, Performance and mechanism of $\mathrm{Mg} / \mathrm{Fe}$ layered double hydroxides for fluoride and arsenate removal from aqueous solution, Chem. Eng. J. 228 (2013) 731-740.

\section{Highlights}

1. Composition-tunable bimetallic Fe/Mg-MIL-88B(n) nanospindles was synthesized.

2. Arsenate uptake capacity up to $303.6 \mathrm{mg} / \mathrm{g}$ is achieved in the optimized Fe/MgMIL-88B(0.5).

3. Regenerative ability and stability of Fe/Mg-MIL-88B absorbents were evaluated.

4. Sorption mechanism of arsenate on the Fe/Mg-MIL-88B(0.5) was studied.

\section{Graphic Abstract}




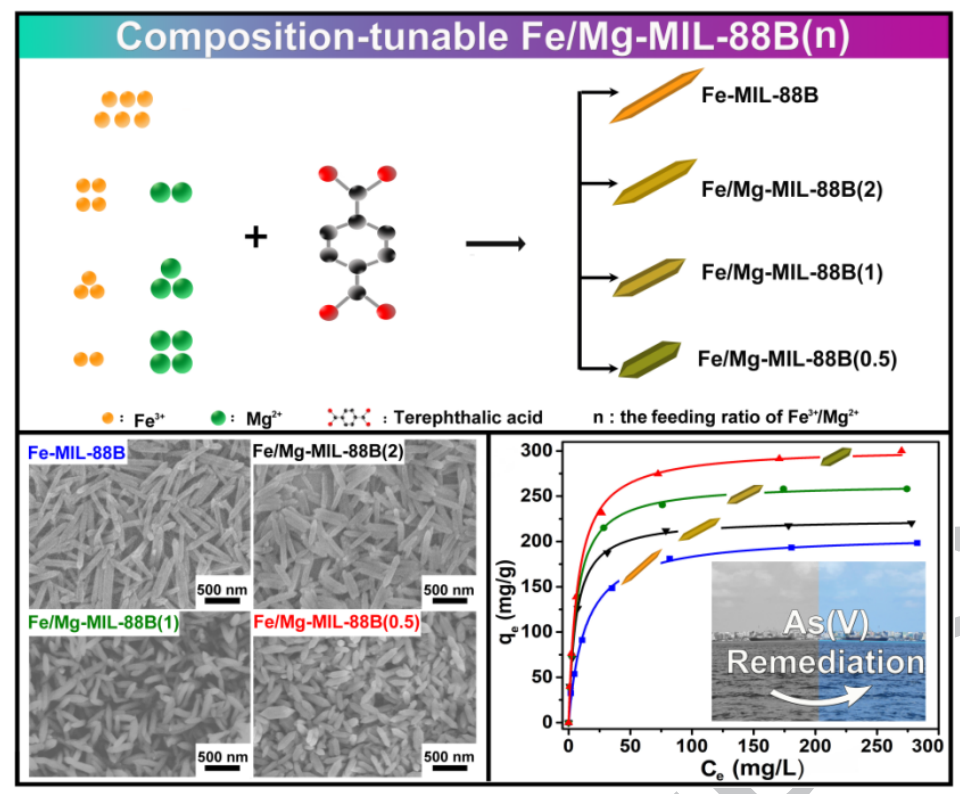




\section{Accepted Manuscript}

Facile fabrication of composition-tunable Fe/Mg bimetal-organic frameworks

for exceptional arsenate removal

Yue Gu, Donghua Xie, Yongchuang Wang, Wenxiu Qin, Haimin Zhang,

Guozhong Wang, Yunxia Zhang, Huijun Zhao

PII:

S1385-8947(18)31888-6

DOI:

https://doi.org/10.1016/j.cej.2018.09.174

Reference:

CEJ 20013

To appear in:

Chemical Engineering Journal

Received Date:

27 August 2018

Revised Date:

19 September 2018

Accepted Date:

21 September 2018

Please cite this article as: Y. Gu, D. Xie, Y. Wang, W. Qin, H. Zhang, G. Wang, Y.Zhang, H. Zhao, Facile fabrication of composition-tunable $\mathrm{Fe} / \mathrm{Mg}$ bimetal-organic frameworks for exceptional arsenate removal, Chemical Engineering Journal (2018), doi: https://doi.org/10.1016/j.cej.2018.09.174

This is a PDF file of an unedited manuscript that has been accepted for publication. As a service to our customers we are providing this early version of the manuscript. The manuscript will undergo copyediting, typesetting, and review of the resulting proof before it is published in its final form. Please note that during the production process errors may be discovered which could affect the content, and all legal disclaimers that apply to the journal pertain. 